\title{
The Dark Side of 'Good' Corporate Governance: Compliance-Fuelled Book-Cooking Activities*
}

\author{
Tom Kirchmaier ${ }^{\dagger} \quad$ Mariano Selvaggi ${ }^{\ddagger}$
}

April 2006

\begin{abstract}
We argue on theoretical grounds that obligatory compliance with stricter financial reporting rules (e.g., the US Sarbanes-Oxley Act) may entail important unintended consequences. Paradoxically, the amount of misreporting may increase because corporate boards spend more valuable resources fulfilling statutory mandates rather than involving themselves in forward-looking strategy setting. As these surveillance devices are substitute methods of gauging management quality, when boards focus on the firm's internal control and accounting system they become semi-detached from strategy - their business acumen falters. Top executives are then judged primarily on the basis of financial metrics as opposed to long-term fit. Since the balance sheet review carries more weight in the board's decision-making process, the return to managerial book-cooking (a purely "influence" activity) and the risk of endorsing flawed business plans swell. This confirms a burgeoning sentiment among business leaders and scholars that boards should perhaps pay less rather than more heed to codified, verifiable 'good' governance principles.
\end{abstract}

JEL classification: D23, G30, K20, M21, M40.

Keywords: Corporate Governance, Earnings Manipulation, Auditing, Misreporting, Sarbanes-Oxley Act, Combined Code on Corporate Governance.

\footnotetext{
${ }^{*}$ Helpful comments by Valentina Bruno, David de Meza, Luis Vanconcelos and seminar participants at the IIM/CEP Management Research Seminar (LSE), Centre for Finance and Management Studies (SOAS), Universidade Nova de Lisboa and Watson Wyatt (Reigate) are gratefully acknowledged.

$\dagger^{\dagger}$ Manchester Business School \& FMG, London School of Economics.

$\ddagger$ Department of Management, London School of Economics, Houghton Street, Office G408, London WC2A 2AE. Tel: +44 (0)207955 7544, e-mail: M.Selvaggi@lse.ac.uk.
} 


\section{Introduction}

For good or ill, the responsibilities of non-executive directors (henceforth "NEDs") have become increasingly formalised and subject to conformance with stricter governance rules and codes of best practice (e.g., the Sarbanes-Oxley Act in the USA and the Combined Code on Corporate Governance in the UK). ${ }^{1}$ In effect the institutional environment for corporate governance seems to be rapidly shifting from self-regulation to compulsory compliance. Particularly, corporate financial reporting and audit committees have been the subject of much regulatory reform. ${ }^{2}$ Yet whether or not this new approach to governance policy ultimately promotes shareholders' value remains a subject of ongoing debate in the business press and academic literature alike. In that connection, it has been argued that stiffer regulatory pressure could have the adverse effect of requiring corporate boards to spend more of their valuable time fulfilling statutory mandates (e.g. "box-ticking") instead of pursuing more productive activities. As a result, the necessary balance between managerial accountability and business health may break down (see, e.g., Keasey et al. 2005). Underlying this assertion is the informal claim that higher workloads prompted by intense scrutiny of the firm's internal control and reporting systems may come at the expense of NEDs' value-enhancing engagement in corporate strategy. As the new governance climate gathers pace, it is thus important to formally examine whether the heightened burden of disclosure requirements and compliance-oriented work, while on the surface understandable, could in reality have inadvertent side-effects.

It goes without saying that the compliance with stricter financial reporting standards entails direct costs for firms (e.g., higher auditing fees). In this paper we contend that other indirect, unrecognised economic costs may in reality play an equally pivotal role. Specifically, public policy changes intended to reduce the extent of misrepresentation may actually "fuel" top management's incentive to manipulate the firm's (formal) internal control and reporting system. As a result, aggregate welfare and the long-term value of the firm may ultimately suffer.

In reality boards are supposed to fulfil a dual role. On the one hand, non-executives have a clear monitoring mandate to oversee/supervise the performance of senior management. To do so, they rely to a large extent on financial statements under the assumption that the accounts provide a true and fair picture of the firm. In addition, and often overlooked, boards spend certain amount of time discussing the critical strategic issues the firm is facing. This dialogue not only enables NEDs to give their advice and share their expert knowledge with top management, but gives board members a much deeper insight into the

\footnotetext{
${ }^{1}$ To an appreciable extent, the stampede to alter corporate governance and reporting requirements was a reaction to highprofile business failures and abuses of executive power on both sides of the Atlantic (e.g., Enron and WorldCom in the US; Parmalat and Ahold in Europe).

${ }^{2}$ For example, the New York Stock Exchange (NYSE) and the Securities and Exchange Commission (SEC) have recently approved new corporate governance rules and standards relating to the work of audit committees (see SR-NYSE-2002-33 and SEC-33-8220, respectively).
} 
major business challenges faced by the firm. In this way NEDs get deeply involved in the key processes of formulating and evaluating corporate strategy. Briefly put, non-executive directors exert both auditing effort and strategic involvement effort (i.e. engagement in the business) when performing their duties.

The trouble is, these two major surveillance devices - or oversight responsibilities - are substitutes methods of gauging management quality even though they need not compete directly for NEDs' time and attention. Hence, when boards focus on the firm's internal control and accounting system they become semi-detached from strategy - their business acumen falters. Top executives are then judged primarily on the basis of financial metrics as opposed to long-term fit. As the balance sheet review carries more weight in the board's decision-making process, the return to managerial book-cooking (a purely "influence" activity) and the risk of endorsing flawed business plans swell. This confirms a burgeoning sentiment among business leaders and scholars that boards should perhaps pay less rather than more heed to codified, verifiable 'good' governance principles. This is because the continual strengthening of NEDs' auditing and accounting obligations may weaken rather than strengthen the board's capacity to gauge the quality of management.

Our conceptual framework comprises NEDs and a top management team, personified as the chief executive officer (CEO). To highlight our main contribution, we completely abstract from executive reward issues and monetary incentives. Further, we shy away from productive effort by management. There exists a burgeoning literature that looks at compensation-driven earnings manipulation, but our interest lies instead in the connected question of how the drain of code compliance affects managerial incentives to "cook the books" the so-called aggressive accounting. To our knowledge, the plausible link between regulatory compliance with tighter reporting obligations and management's incentive for financial misreporting remains by and large unexplored.

The interest of non-executives is assumed to be perfectly aligned with that of the shareholders. There does exist a basic conflict of interest between NEDs and management, however, because the CEO wishes to hold a tight grip on her position and hamper value-enhancing replacement. To counter the underlying problem of asymmetric information, non-executives assess executive performance in two different ways: auditing the financial information produced by senior management, and being engaged in the company's strategy definition and implementation. NEDs' auditing effort produces verifiable "hard" evidence of the veracity of the company's financial statement whereas NEDs' involvement in strategy permits a sound judgement of the business plan pursued by management. ${ }^{3}$ With these surveillance mechanisms we attempt to resemble the observed board's role of monitoring short-term financial performance and appraising longer-term business initiatives - possibly the two major responsibilities of NEDs apart from setting remuneration policies.

To highlight in a stark way the gist of our analysis, we assume that the CEO only exerts unobservable

\footnotetext{
${ }^{3}$ As we explain in the next section, an audit of the accounts is performed by an external auditor who never fails to act in the interest of the board. Hence no incentive problems arise at the audit level.
} 
"book-cooking" effort. This activity brings no benefit to the company; its sole objective is to conceal weak performance through influencing the auditing procedure's effectiveness. Therefore, book-cooking could be interpreted as time spent trying to influence the composition of the audit committee, or exploiting loopholes in the firm's accounting system, or eliciting cooperation along reporting lines so as to achieve a workable misreporting scheme. ${ }^{4}$ Its sole objective is to make an audit failure more likely.

In this context, our main contention is that allegedly 'good' governance principles such as progressively more stringent auditing obligations may in fact fuel unproductive book-cooking effort by top management. That is, stricter "formalised" control can have the paradoxical effect of weakening "effective" control within organisations.

We show that even though the two surveillance devices do not make competing demands for NEDs' time and attention because there is no interaction in the private cost function, raising auditing effort above the optimal level to comply with legal requirements results not only in less strategic involvement by non-executive board members (i.e. less effort expended in developing and overseeing the corporate strategy), but equally important in a higher amount of management's influence activity. As a result, the long-term value of the business may ultimately suffer. This basic result is consistent with existing arguments suggesting a potential negative impact of excessive compliance regulation on shareholders' wealth. For instance, the majority of chairmen from FTSE 100 companies surveyed by Russell Reynolds Associates during 2005 did not believe increasingly burdensome governance regulation have had a positive impact on company performance. ${ }^{5}$ The reasoning provided in this paper is more subtle, though: the compliance with tighter audit compliance reduces the attractiveness of strategic involvement, so less of it takes place in a constrained equilibrium where board members use more intensely the relatively less efficient monitoring technology.

Our model also captures the notion that the strategic focus of the board's role is essential for long-term value, and code compliance should be developed in a carefully crafted way. ${ }^{6}$ If boards allow the latter to dominate, it can have the unintended consequence of destroying value.

The paper proceeds as follows. Section 2 explains the basic ingredients of our analytical framework. Section 3 considers a simplified version of our model in which non-executive board members can only choose the firm's audit intensity in order to evaluate management performance. Proposition 1 formalises one of the main messages of this paper - a higher probability of audit could actually induce more book-cooking activity by top management. Section 4 then proceeds to examine a richer milieu where NEDs can also choose the level of engagement in corporate strategy so as to competently assess executive fit. Proposition 4

\footnotetext{
${ }^{4}$ In our particular context, the influence activity could be managerial time or attention devoted to devising subterfuges to exploit the flexibility of generally accepted auditing standards (GAAS) and generally accepted accounting principles (GAAP).

${ }^{5}$ The Chairman's Report, Russell Reynolds Associates, November 2005.

${ }^{6} \mathrm{~A}$ similar sort of recommendation has been put forward by Roberts and Young (2005) in their report on "The Role of the Board in Creating a High Performance Organisation."
} 
shows that in this context tighter auditing obligations not only fuel managerial book-cooking, but also stifle non-executives' understanding and shaping of the company's business plan. Hence financial review of top management substitutes for their operating/executive review.

\section{Setup and timing}

Consider a group of non-executive board members (henceforth "B"), whose interest is perfectly aligned with that of the shareholders, and a top management team (henceforth "M"). For simplicity, assume that M stands for the chief executive officer (CEO) and that shareholders have perfectly congruent objectives - to maximise the company's net returns. The company has financial resources accumulated in previous periods whereas $\mathrm{M}$ lacks wealth and is protected by limited liability. The latter will ensure that management cannot be contractually induced to report truthfully (of which more later). All agents are assumed risk neutral and, to keep things simple, we dispense with discounting.

Our model comprises three periods, indexed $t=0,1,2$. This is depicted in Figure 1. Roughly speaking, in the first period, $t=0$, the board appoints a CEO to delineate and implement a strategy or business plan. Implementation of the envisaged strategy is a risky business because there is chance that it fails owing to exogenous factors (maybe a technological shift in the market in which the firm operates dooms its business model to failure). After learning the outcome of implementation in the second period, $t=1, \mathrm{M}$ may attempt to report inflated earnings so as to show good managerial performance and hamper her replacement. After observing the financial statement produced by M, board members choose two "surveillance" mechanisms: audit intensity and engagement in strategy. These monitoring technologies attempt to reflect two major oversight responsibilities of NEDs, namely, accounting/financial and operating/business review of senior management. At the beginning of the last period, $t=2$, B makes a replacement decision based on the outcome of the monitoring process. The long-term value of the business plan is then realised and all parties collect their respective payoffs. The details of each period are further explained below.

As it will become more clear shortly, in our model all effort choices entail social losses because they are costly for the agent involved but do not enhance allocative efficiency. This is not too restrictive because this paper abstracts from welfare analysis, although there are several ways in which we could extend our conceptual framework so as to bring welfare implications to the fore. See the Conclusion for more on this important issue.

\subsection{Appointment}

In period $t=0, \mathrm{~B}$ appoints a $\mathrm{CEO}$ from a large pool of potential managers. The job of the CEO is to delineate a business plan (or strategy statement) and carry out its implementation in period $t=1$. The 


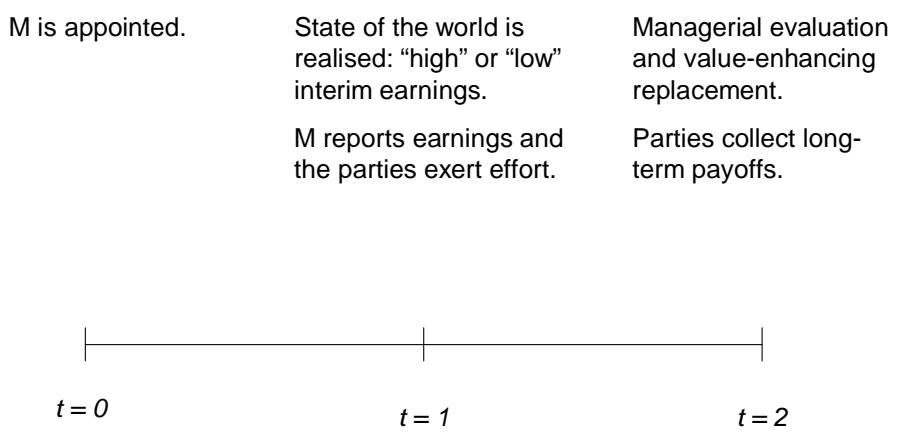

Figure 1: Sequence of events.

appointed CEO does her best to successfully implement the envisaged corporate strategy and yet the state of nature ultimately determines this outcome. We model this as a random variable $\theta$ that can take only two values, $\theta^{S}$ in case of success and $\theta^{F}$ in case of failure. Think of $\theta$ as the CEO's long-term suitability to the job, e.g., her cultural fit or leadership prowess. Alternatively but equivalently, $\theta$ could be interpreted as the ultimate soundness of the manager's "vision" of the likely evolution of the market in which the firm operates. At the outset, neither party knows the value of $\theta$ although there is a common belief that with probability $p_{i}$ state $i \in\{S, F\}$ will occur, with $p_{i}>0$ and $p_{S}+p_{F}=1$. As all parties agree on the same prior at the time the $\mathrm{CEO}$ is hired, no adverse selection problem arises at this stage. ${ }^{7}$

Let $\alpha$ denote the proportion of potential executives who behave selfishly and always maximise expected utility. If the need arises, these managers will be willing to cook the books to gain an advantage. (1 $-\alpha)$ stands in turn for the proportion of "ethical" managers, who under no circumstances would rig accounting figures or commit fraud. These managers always report truthfully irrespective of their personal interest in the final outcome. The characteristic of a manager is unobservable to B.

To highlight our main point, we abstract from issues of incentives (i.e. productive effort) and executive rewards: M's next best alternative is normalised to zero and she works for the firm so long as her salary

\footnotetext{
${ }^{7}$ In Rotemberg and Saloner (2000), CEOs are also born with a "vision" of what is best for the firm although in their case the strategic direction is biased: the CEO's favoured business strategy differs from the one that maximises profits. In our model there is no bias ex ante. Besides, Rotemberg and Saloner focus on organisational behaviours that are completely different from the ones that are to the fore in this paper.
} 
is non-negative. In this way we disentangle misreporting from compensation packages and bring under harsh spotlight the difference between our approach and prior contributions that stress the link between earnings manipulation and performance-based pay (see, e.g., Goldman and Slezak (2005) and Bergstresser and Philippon (2006)). In those papers the incentive to manipulate earnings stems from the fact that management's compensation or tenure depends on earnings-driven performance measures. In our model, however, $\mathrm{M}$ values her position because she collects an unobservable private benefit $b>0$ if she is retained in period $t=2$ (more on this shortly). Think of $b$ as perks, corporate funds diverted to senior management or pension payout that $\mathrm{M}$ collect if they stay up to liquidation. While M's compensation package plays no role in our analysis, it is not difficult to ponder extensions in which socially valuable effort and efficient contracting are taken on board. We leave this for a sequel, though.

\subsection{Implementation and reporting}

The details of periods $t=1$ and $t=2$ are depicted in Figure 2. At the beginning of period $t=1$, the realisation of $\theta$ becomes private information to $\mathrm{M}$ - after all, the CEO deals with the firm's processes and operations on a day-to-day basis. In addition, the business generates interim earnings: $E^{h}>0$ (high) if $\theta=\theta^{S}$ and $E^{l}=0$ (low) if $\theta=\theta^{F}$. All this is common knowledge. At this point board members only access a report on actual earnings, $\hat{E}^{j}=E^{j} j \in\{h, l\}$, produced by M. For expositional reasons, we call $\hat{E}$ the firm's financial statement albeit more general interpretations are also possible $(\hat{E}$ could be, for example, a management earnings forecast or a formal estimate of oil/gas reserves).

To evaluate managerial incentives to misreport earnings, we must consider what would happen if $\mathrm{M}$ truthfully reported low earnings. As it will become clear shortly, in our model shareholders will always be better off replacing non-performing management. This makes our analysis non-trivial by creating a conflict of interest between B and M. Particularly, when $\theta=\theta^{F}$ selfish management will produce "dodgy accounts" in order to secure a tighter grip on $b$.

Anticipating this behaviour, NEDs rely on two surveillance devices to catch non-performing management: "auditing effort" and "involvement in strategy". The former represents the extent to which reported earnings are publicly scrutinised. Specifically, members of the audit committee choose $A \in[0,1]$ at a cost $A^{2} / 2$. This verification scheme enables $\mathrm{B}$ to execute an independent audit of reported earnings with probability $A$. The audit intensity should be interpreted broadly: it could be the soundness of the firm's financial reporting and disclosure mechanisms, the degree to which the firm abides by auditing procedures and accounting techniques enshrined in Acts and Codes, or the strictness of the formal internal and external control system. ${ }^{8}$ In what

\footnotetext{
${ }^{8}$ In the interpretation we have in mind, $A$ may also be viewed as the extent to which board members are in a position to exercise a knowledgeable judgement on accounting and reporting issues, or on non-traditional accounting techniques used by the top management.
} 


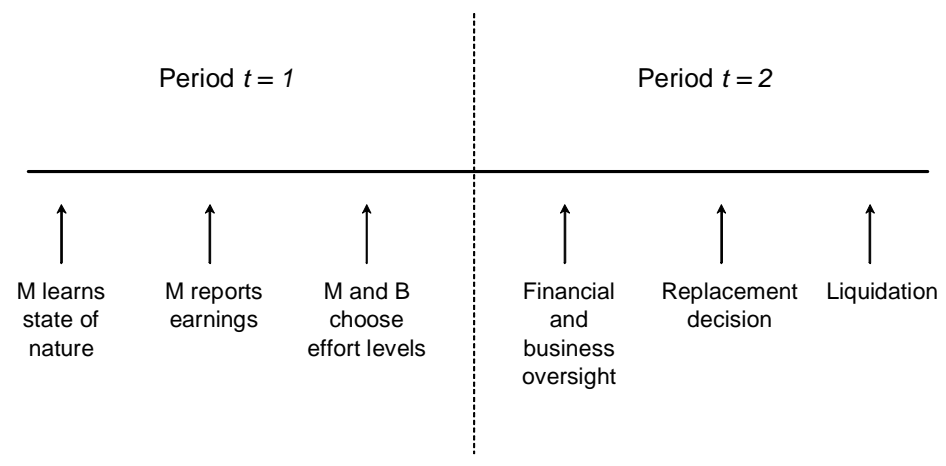

Figure 2: Sequence of events

follows, we refer to $A$ as the board's audit policy.

When an audit is executed, it reveals real earnings with probability $1-\sigma(C)$ but does not challenge reported earnings with the complementary probability, where $C \geq 0$ represents (unobservable) "book-cooking" effort exerted by $\mathrm{M}$ at private cost $C^{2} / 2$. Think of $C$ as time spent unproductively trying to influence the composition of the audit committee, or exploiting loopholes in the firm's accounting system, or eliciting cooperation along reporting lines so as to achieve workable misreporting. $C$ is, in effect, an influence activity that brings no benefit whatsoever to the organisation (see Milgrom and Roberts (1988)). ${ }^{9}$ In our setup, the source of influence is M's capability to interfere in the effectiveness of the audit policy. Following Newman et al. $(1996,2005)$, we make the following assumption regarding the non-detection probability, $\sigma$.

Assumption $1 \sigma(C)=1-e^{-C}$.

Hence, as the level of managerial book-cooking approaches 0 , the probability of affecting the effectiveness of the firm's control system also goes to 0 . As $C$ approaches infinity, however, the manager affects the effectiveness of the audit process with probability $1 .^{10}$ The audit of reported earnings is assumed to be free,

\footnotetext{
${ }^{9}$ In our context, the influence activity could be managerial time or attention devoted to devising subterfuges to exploit the flexibility allowed in generally accepted accounting principles (GAAP).

${ }^{10} \mathrm{It}$ is widely recognised that there are limits to auditors' ability to detect accounting fraud, especially when it involves collusive behaviour among executives and acquiescence along reporting lines.
} 
impartial and verifiable in court - this essentially brushes away additional moral hazard issues in the auditing technology that are immaterial to our story. No audit failure penalty is imposed on the auditor in case the accounting fraud is discovered in later (unmodelled) periods.

The other surveillance mechanism used by B, engagement in strategy, captures the extent to which nonexecutive board members can produce a sound judgement of the firm's business model. Specifically, NEDs choose $S \in[0,1]$ at a cost $S^{2} / 2$. This "operating audit" enables board members to learn $\theta$ with probability $S$. Thus, information-acquisition investment $S$ can be viewed as time or attention devoted by B to assessing corporate strategy, or acquiring/sharpening an expert knowledge of the business, or monitoring stringently the initiatives proposed by senior management. In what follows, we refer to $S$ as the board's involvement or engagement in corporate strategy.

\subsection{Managerial replacement and long-term payoffs}

At the beginning of period $t=2$, non-executives observe the outcome of monitoring and decide whether or not to replace M. Subsequently the business project is liquidated. M is fired in three possible circumstances: (1) when low earnings are reported, (2) when B challenge the veracity of the financial statement, and (3) when $\mathrm{B}$ learn $\theta$. As a result, only ethical managers truthfully report low earnings.

More particularly, if $\mathrm{M}$ is replaced before the project is liquidated, then all parties get 0 (gross of investment costs). ${ }^{11}$ We assume that in this case the CEO just retires and faces no stigma whatsoeverthere are no economic or moral penalties for false reporting. In the absence of managerial replacement, the firm's (net) incremental liquidation proceeds are $\pi^{S}=\Pi-b>0$ in case of successful implementation and $\pi^{F}=-b$ otherwise. These terminal values are neither verifiable nor subject to managerial manipulation, what seems realistic if the long run (represented by period $t=2$ ) is far enough in the future so as to make contracting infeasible. Note that $b$ reduces the total payout to the owners upon liquidation. Hence, $\pi$ may be interpreted as the discounted value of the future stream of benefits generated by a successful business plan or the long-term market value of the company under competent management. ${ }^{12}$

\footnotetext{
${ }^{11}$ The underlying logic is that a different set of CEO's capabilities is needed to reorganise or redeploy the organisation's assets after flawed implementation of the envisaged strategy.

${ }^{12}$ Alternatively but equivalently, our model could be built upon the assumption that the CEO intially chooses between two unverifiable projects, A and B say: both yield $b$ to the CEO, whereas project A yields $\pi>0$ to the shareholders and project B yields $-b$. Thus, as in Burkart et al. (1997), there exists a conflict of interest between the manager and the shareholders but non-executives cannot distinguish between the projects without further action.
} 


\section{A simple case}

As a first step, in this opening section we dispense with $S$ and fix attention on the other two endogenous variables of our model: management's book-cooking activity, $C$, and NEDs' audit policy, $A .{ }^{13}$ This yardstick case will enable us to isolate basic mechanisms at work in a relatively simple environment. Later, once these effects are better understood, we move on to examine a richer and more realistic setting in which NEDs' involvement in strategy also plays a role.

Figure 3 depicts the game tree; for simplicity, the parties' payoffs have been omitted. The first two nodes are chance moves that determine the type of manager hired and the outcome of the implementation, respectively. The incumbent CEO, who is privy to all this information, then produces a financial report $\hat{E}^{j}$ (denoted by $h, l$ ) and subsequently the board chooses an audit policy (denoted by $a, n$ ). As usual, the dotted line represents an information set, so these nodes are indistinguishable to non-executive members of the board. Due to the absence of enforceable penalties for misreporting, a non-ethical CEO who faces unsuccessful implementation will be willing to perpetrate accounting fraud because in the worst-case scenario she is caught sacked. As we show below, the amount of managerial book cooking generally depends on B's audit policy. A sufficiently high fine for breaching financial reporting obligations may deter M from misreporting, of course, albeit this situation does not seem to accord with reality.

To simplify notation, let $p_{S}=p$ and $p_{F}=1-p$. Since non-executives cannot distinguish between an honest and a dishonest CEO, they use the veracity of accounting figures as an imperfect proxy of managerial performance. Particularly, the gains from auditing depend on the distribution of sincere and insincere managers among all those who report high earnings. To be more concrete, consider the case of an unsuccessful manager who fiddles with the accounts in order to secure a tighter grip on her position. Calling $\beta$ the probability attached to the event that a CEO who reports high earnings actually disguises low earnings, a straightforward application of Bayes' law implies that

$$
\operatorname{Pr}\left(\theta=\theta^{F} \mid \hat{E}=E^{h}\right) \equiv \beta=\frac{\alpha(1-p)}{p+\alpha(1-p)}
$$

Using Figure 3, it is readily seen that (3.1) represents the probability of being in the middle node given that NEDs know they are at their information set. Effectively, the probability that a manager reports fictitious high earnings is $\alpha(1-p)$ because honest or successful managers never misreport. This explains the numerator of (3.1). As to the denominator, note that a manager reports high earnings in two possible situations: when there is sound implementation of the envisaged strategy (which occurs with probability $p$ ) or when there is flawed implementation and $\mathrm{M}$ uses deceitful accounting to pump up performance (which occurs

\footnotetext{
${ }^{13}$ The firm's probability of audit, or auditing intensity, can be interpreted as internal control systems and governance mechanisms, as mandates originated in an external regulatory agency responsible for enforcing financial reporting obligations, or as a combination of both. We shall come back to this issue later, when we deal with corporate governance rules.
} 


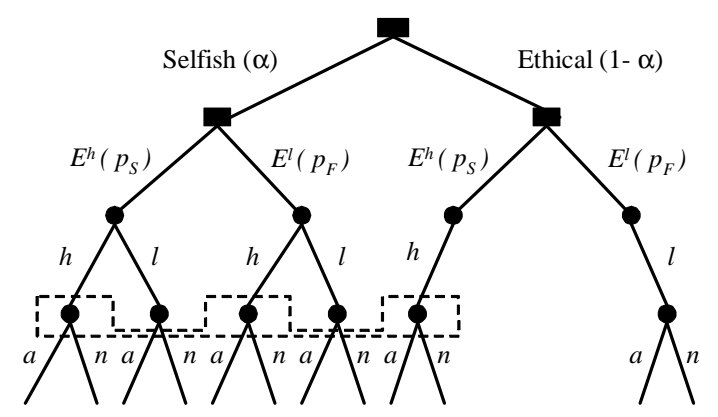

The "book-cooking" game. Exogenous chance moves are denoted by squares.

Figure 3: Game tree.

with probability $\alpha(1-p))$. This explains the denominator of $(3.1)$. Observe that $\beta_{\alpha}=p(1-p) / \phi^{2}>0$ and $\beta_{p}=-\alpha / \phi^{2}<0$, where subscripts stand for partial derivatives and $\phi=p+\alpha(1-p)$. Not surprisingly, the probability that high earnings are actually fabricated decreases with the proportion of ethical managers in the whole population and increases with the difficulty of successful implementation.

Following Graetz et al. (1986), Melumad and Mookherjee (1989) and Khalil (1997), among others, we posit that B cannot commit themselves to an audit strategy in advance. Auditing has to be sequentially optimal because it is in the board's best interest to decide whom to audit only after financial disclosure takes place (i.e., in a properly defined continuation subgame). ${ }^{14}$ Hence a strategy for the board is simply the likelihood of auditing the accounts of a manager who reports high earnings, since there is no point in auditing a manager who (truthfully) reports low earnings. Note that, as opposed to the literature on tax compliance, in our model the incentive to audit does not stem from the collection of a penalty but rather from the opportunity to replace non-performing management. In this way shareholders avoid losing $b$. Therefore, given $C$, in period $t=1$ non-executives select an audit policy so as to maximise the firm's expected payoff:

$$
\Psi=A\{\beta[(1-\sigma) 0-\sigma b]+(1-\beta) \pi\}+(1-A)\{-\beta b+(1-\beta) \pi\}-A^{2} / 2
$$

\footnotetext{
${ }^{14}$ As mentioned in Section 2, we assume throughout that the firm's cost of actually carrying out an audit of the accounting figures is zero. If, quite realistically, we had assumed instead that the auditing procedure entails costs, then a time-consistency problem would have arised and the possibility to commit to an audit policy would have been even more questionable.
} 
The first term is the expected gain from auditing high earnings, taking into consideration management's book-cooking activity, whereas the second term gives the firm's expected revenue when no audit takes place. Re-arranging, we have that

$$
\Psi=\pi(1-\beta)-b \beta[1-A(1-\sigma)]-A^{2} / 2
$$

In words, the first term in this expression represents the certain revenue that accrues to the company if no audit is performed. The other two terms capture the expected return from an inspection, net of audit expenditures (the ex post gain from an audit of high accounting earnings is $b$ ). Expression $A(1-\sigma)$, the "effectiveness" of the audit policy chosen by the board, lies at the centre of our approach and will resurface repeatedly throughout this paper.

Using the FOC, we have that B's optimal amount of audit resource investment is given by

$$
A^{*}=b \beta(1-\sigma)=\frac{b \alpha(1-p)(1-\sigma)}{p+\alpha(1-p)}
$$

Thus, other things being equal, the probability of audit increases with (a) the amount of corporate funds diverted by management (e.g., perks), and (b) the proportion of non-ethical managers in the whole population. On the other hand, the marginal benefit of auditing decreases with (a) the probability of successful implementation, and (b) the amount of book-cooking effort exerted by management. ${ }^{15}$

Next, consider the problem faced by senior management who behave so as to maximise expected utility. Confronted with flawed implementation of the envisaged strategy, this sort of CEO will overstate true performance in an effort to keep her job. As mentioned above, this is partly because we abstracted from penalties for managerial wrongdoings. Therefore, given a probability of audit $A$, an unethical manager chooses $C$ so as to maximise

$$
B=A[(1-\sigma) 0+\sigma b]+(1-A) b-C^{2} / 2
$$

After basic algebraic manipulations, the above expression can be re-written as follows:

$$
B=b[1-A(1-\sigma)]-C^{2} / 2
$$

This simply says that in the presence of flawed implementation, the incumbent CEO contrives to collect $b$ when beefed-up accounting figures are not challenged during an audit process, which occurs with probability $[1-A(1-\sigma)]$. Thus, the FOC for the manager yields

$$
C^{*}=b A \sigma^{\prime}
$$

\footnotetext{
${ }^{15}$ If NEDs could commit to and audit strategy at the outset, it would be the solution to the following programme:

$$
\max _{\{A\}} \pi p-b(1-p)[1-A(1-\sigma)]-A^{2} / 2
$$

which gives rise to the FOC $A^{c}=b(1-p)(1-\sigma) \neq A^{*}$. This vindicates our previous claim that the probability of audit chosen by the board in period $t=0$ is not generally subgame-perfect or sequentially optimal.
} 
where $\sigma^{\prime}$ stands for $\partial \sigma / \partial C=e^{-C}$. Interestingly, the board's audit policy creates an incentive problem: the time or effort expended by $\mathrm{M}$ to achieve a workable misreporting scheme, $C$, actually "increases" with $A$. This provocative conclusion stems from the fact that a higher probability of audit, rather than discouraging managerial fraud, actually boosts the return to M's book-cooking activity. As non-executives rely more heavily on accounting figures to judge management performance, the marginal return to M's influence on the firm's formal control system swells. The simple reason is that the accounting chicanery is more likely to influence the board's replacement decision.

Based on the best-response functions (3.2) and (3.3), we can calculate the Nash equilibrium configuration. In that connection, the following assumptions ensure that feasible solutions always obtain.

\section{Assumption $20<b \leq 1$.}

When the above assumption holds and managerial value diversion is not too large, we have that $0 \leq$ $A^{*} \leq 1$.

The next proposition records one of the main conclusion of this section.

Proposition 1 Management book-cooking (influence) activity, $C$, is non-decreasing in the audit intensity $A$. In the presence of interior solutions, $C$ strictly increases with $A$.

Proof. The result follows directly from (3.2), (3.3) and Assumption 2.

Paradoxically, a higher audit intensity induces top management to spend larger amounts of (unproductive) time and attention trying to influence the firm's control systems. Accounting-led boards fuel managerial book cooking because NEDs provide non-performing managers with an opportunity to influence the firm's formal decision-making process. Underlying this conclusion is a basic informational asymmetry. Specifically, non-executives do not have all the information needed to make a good decision on replacement whereas management has both the required information and an interest in the final outcome. In this context, a higher probability of audit boosts M's incentive to spend resources on book cooking in order to turn the board's decision to her advantage.

The following comparative-static result formally records how changes in the underlying parameters of the model affect the equilibrium values of the two endogenous variables. The subsequent discussion provides intuitive explanations for these findings.

Proposition 2 In equilibrium, we have that

1. $\partial A / \partial \alpha>0$ and $\partial C / \partial \alpha>0$ 
2. $\partial A / \partial p<0$ and $\partial C / \partial p<0$;

3. $\partial A / \partial b>0$ and $\partial C / \partial b>0$.

Proof. See Appendix.

An increase in the proportion of ethical managers, $1-\alpha$, is beneficial because B and $\mathrm{M}$ expend fewer valuable resources on accounting-related activities. Since high reported earnings are less likely to have been artificially inflated, B audits less intensively which in turn discourages management book cooking. An upward shift in $p$ moves the endogenous variables in a similar direction: when this probability increases, it is less likely that a CEO who informs high earnings is actually misreporting. In consequence, NEDs have less incentive to scrutinise management through auditing and the marginal return to managerial book-cooking plummets. As to the personal benefit collected by the manager, $b$, its effect is similar to an increase in $\alpha$ : the benefit from an audit as well as the marginal return to book-cooking each go up with $b$.

As to public policy implications for corporate governance legislation, suppose we impose the constraint $A \geq \bar{A}$ on this basic model. This case might arise, for example, when the intensity of corporate auditing is subject to external governance regulations. In the presence of an additional restriction, it is evident that the company cannot do better than without it. More precisely, if the constraint on the audit probability is non-binding then, of course, the equilibrium configuration is exactly as described above. If $A^{*}<\bar{A}$, however, the board would like to audit less than the legally enforceable level required by corporate reporting requirements. It is worth stressing that the higher probability of audit is actually dysfunctional because it induces management to spend more of their time influencing the firm's formal surveillance process. In consequence, society as a whole is unambiguously worse off.

Given this negative result, it is important to briefly discuss other possible ways to hinder fraudulent and/or unethical behaviour by senior management. According to 2, greater transparency of disclosure could also be achieved having more ethical managers. In the longer term at least, $1-\alpha$ is sensitive to governmental intervention such as content of executive education programmes (e.g., business ethics or CSR) and more general social policies. Another way of improving the informativeness of corporate reporting entails enhancing the efficacy of audit. In effect much of recent corporate governance legislation is aimed at improving the quality of corporate financial statements. To tackle this issue, suppose the non-detection probability takes the form $\sigma(C)=1-e^{-\lambda C}$, where $\lambda \in[0,1]$ captures the "productivity" of managerial book-cooking. Our previous results refer to the case in which $\lambda=1$. As $\lambda$ approaches 0 , however, the manager becomes relatively less effective in influencing the probability with which accounting tricks are uncovered during an audit. Intuition might suggest that as $\lambda$ becomes smaller, the amount of book-cooking activity also slumps. Yet the following proposition shows that this need not necessarily be the case. 
Proposition 3 Suppose that $\sigma(C)=1-e^{-\lambda C}$. In equilibrium, we have that $\partial A / \partial \lambda<0$ and $\partial C / \partial \lambda \gtrless 0$.

Proof. From (3.2) - (3.3), we obtain:

$$
\left[\begin{array}{cc}
1-b A \sigma_{c c} & -b \sigma_{c} \\
b \beta \sigma_{c} & 1
\end{array}\right]\left[\begin{array}{c}
d C \\
d A
\end{array}\right]=\left[\begin{array}{c}
b A \sigma_{c \lambda} d \lambda \\
-b \beta \sigma_{\lambda} d \lambda
\end{array}\right]
$$

where subscripts stand for partial derivatives. Let $D>0$ be the determinant of the first matrix on the l.h.s. of this expression. Then, straightforward applications of Cramer's rule and the Implicit Function Theorem imply that

$$
\begin{aligned}
\partial C / \partial \lambda & =\frac{b A \sigma_{c \lambda}-b^{2} \beta \sigma_{c} \sigma_{\lambda}}{D} \\
& =\frac{b^{2} \beta e^{-2 \lambda C}(1-2 \lambda C)}{D} \gtrless 0
\end{aligned}
$$

and

$$
\partial A / \partial \lambda=\frac{-\left[1-b A \sigma_{c c}\right] b \beta \sigma_{\lambda}-b^{2} \beta A \sigma_{c \lambda} \sigma_{c}}{D}<0
$$

Hence the probability of audit and the amount of influence activity may sometimes increase as $\lambda$, the productivity of managerial book-cooking, decreases. The logic behind this surprising result is the following. A fall in $\lambda$ gives rise to two opposite effects on the return to $C$. For one thing, the marginal unit of bookcooking effort becomes less attractive and management has an incentive to cut it. This reflects a direct impact of $\lambda$ on $C$. For another thing, board members respond to a drop in $\lambda$ by increasing the probability of audit, which in turn boosts the marginal benefit from book-cooking. As it turns out, when $\lambda$ is relatively high the latter (indirect) effect may dominate and a small reduction in $\lambda$ provokes increases in both endogenous variables. In such circumstances, the effectiveness of the auditing procedure suffers even though managerial book cooking becomes relatively less productive.

\section{The model}

In this section we convey the whole gist of our analysis by allowing non-executive board members to also choose the extent of their engagement in the strategic direction of the company. Recall that the choice variable $S \in[0,1]$ enables members of the board to correctly assess the quality of implementation with probability $S$. The cost of NEDs' involvement in strategy is $S^{2} / 2$.

Four possible situations may arise in this setup. First, if the business model performs well and earnings are positive, then the incumbent CEO is retained. For successful managers always report truthfully. Second, 
if the business model performs badly and board members are strategically knowledgeable, then managerial replacement ensues irrespective of reported earnings. On these occasions M may inflate earnings, but this is inconsequential because non-executives' business knowledge enables them to replace non-performing management. The third and fourth cases refer in turn to situations in which there is flawed implementation but NEDs cannot directly assess corporate strategy. In such circumstances some managers will perpetrate fraud in an attempt to avert accountability and non-executives' decision-making process will depend entirely on the outcome of the balance sheet review. Hence, with probability $1-\sigma$ the accounting subterfuge is uncovered and the manager is fired, whereas with probability $\sigma$ the trick is not detected and non-executives endorse duff business plans - an instance of a type-II error. ${ }^{16}$ The latter represents the "risk of business failure" faced by ill-equipped-i.e. poorly-informed-NEDs.

A crucial thing to notice is that presently the probability attached to the event that board members cannot use their business knowledge to spot a flawed implementation of the corporate strategy is given by (in this case high reported earnings disguise poor performance):

$$
\operatorname{Pr}\left(\theta=\theta^{F} \mid \hat{E}=E^{h}\right) \equiv \hat{\beta}=\frac{\alpha(1-p)(1-S)}{p+\alpha(1-p)}
$$

Hence $\hat{\beta}=\beta(1-S)$. The numerator stems from the fact that a manager who reports fictitious high earnings cannot be directly assessed by the board ex post with probability $\alpha(1-p)(1-S)$, because "ethical" managers pay no heed to their pecuniary interest and always report truthfully. As to the denominator, note that management report high earnings either when there is sound implementation of the business plan (which happens with probability $p$ ) or when there is flawed implementation and deceitful accounting is used (which happens with probability $\alpha(1-p)$ ). The intuition behind (4.1) can also be grasped with the help of Figure 4 , where $y$ (respectively, $n$ ) means the board can (respectively, cannot) directly assess the implementation outcome. When NEDs reach their information set, the expected gains from auditing hinge on the likelihood that the board cannot gauge the quality of management by other means. In these circumstances and audit carries all the weight in the board's decision-making process. To obtain (4.1), note that the probability of being in the node on the right-hand side of the middle (dotted) box is $\alpha(1-p)(1-S)$ while the probability of being at the information set is $p+\alpha(1-p)$. Not surprisingly, we have that $\hat{\beta}_{S}=-\beta<0$. Within this richer framework, the conditional probability that fabricated earnings are detected exclusively during an audit decreases with NEDs' strategic involvement - both surveillance devices are substitutes.

The aforementioned implies that, given $C$, in period $t=1$ non-executives choose $A$ so as to maximise the expected net benefit from an audit:

$$
\hat{\Psi}=\pi(1-\beta)-b \beta(1-S)[1-A(1-\sigma)]-A^{2} / 2
$$

\footnotetext{
${ }^{16}$ Alternatively, $\sigma$ could be viewed as the probability of reporting high earnings when the manager actually generates low earnings. In this interpretation, the CEO's choice variable is $\sigma$ rather than $C$.
} 


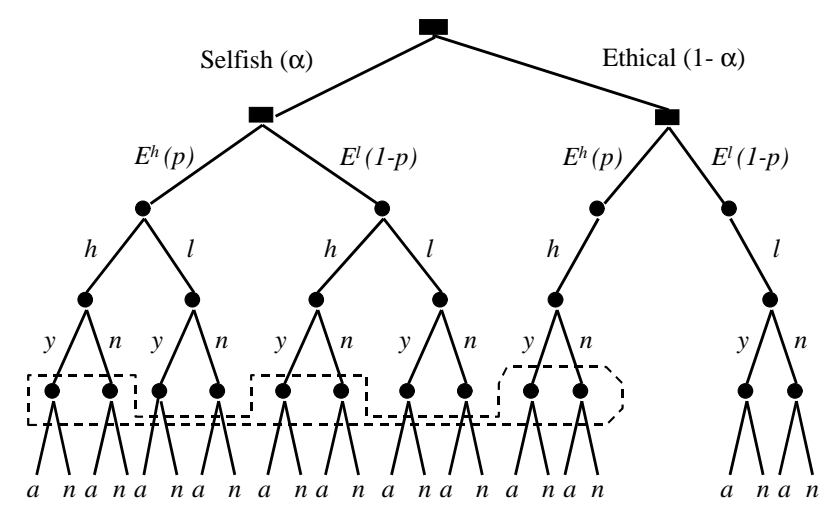

Figure 4: Game tree with strategic involvement.

In the case under consideration an audit of the accounts matters only when non-executives cannot directly asses the quality of strategy implementation. As a result, the optimal amount of audit resource investment comes down to

$$
\hat{A}^{*}=b \hat{\beta}(1-\sigma)=\frac{b \alpha(1-p)(1-S)(1-\sigma)}{p+\alpha(1-p)}
$$

Equation (4.2) confirms our previous assertion that, other things being equal, the board's surveillance mechanisms are substitutes at the margin. Namely, the relative attractiveness of an independent audit decreases with the level of NEDs' involvement in strategy. As we shall see, the board's business initiative is also a superior monitoring technology because it mutes management's incentive to engage in book-cooking influence activities.

Consider the problem faced by a $\mathrm{CEO}$ who acts in her best personal monetary interest. In the presence of sound implementation, the manager does not need to fabricate earnings to show favourable results. Hence $C=0$ in this case. In the presence of poor implementation, and given $S$ and $A$, the manager chooses $C$ so as to maximise her expected utility:

$$
\hat{B}=b\{(1-S)[1-A(1-\sigma)]\}-C^{2} / 2
$$

Effectively, in case of business failure management divert $b$ to themselves only if NEDs cannot judge the soundness of the business plan and beefed-up accounts are not challenged during the audit process. All this 
happens with probability $(1-S)[1-A(1-\sigma)]$. Thus, the manager's FOC yields

$$
\hat{C}^{*}=b(1-S) A \sigma^{\prime}
$$

As $C$ stands for M's unproductive effort or resources expended in trying to achieve a workable misreporting scheme, (4.3) says that management's influence on the company's formal control system decreases with NEDs' involvement in strategy. This is because, as opposed to the simpler case examined in the previous section, in the presence of strategy-led boards the accounting chicanery is less likely to impinge on NEDs' replacement decision. Thus the marginal return to M's book-cooking activity plunges. Conversely put, boards semidetached from strategy rely more heavily on performance metrics based on reported earnings, which in turn boosts the return to M's influence activity. The firm's risk of business failure thus soars.

The next intermediate result follows directly from $(4.2)-(4.3)$.

Lemma 1 Both $\hat{A}^{*}$ and $\hat{C}^{*}$ decrease with non-executives' engagement in strategy, $S$.

Proof. It proves convenient to start with $C$. Specifically, differentiate totally (4.3) to obtain

$$
d C\left[1+2\left(b \sigma^{\prime}\right)^{2} \beta(1-S)\right]=-2\left(b \sigma^{\prime}\right)^{2} \beta d S
$$

which implies that

$$
\frac{\partial C}{\partial S}=-\frac{2\left(b \sigma^{\prime}\right)^{2} \beta}{1+2\left(b \sigma^{\prime}\right)^{2} \beta(1-S)}<0 .
$$

As to $A$, note that the total differential of (4.2) gives rise to the following expression

$$
d A=b\left[\beta_{S}(1-\sigma)-\beta \sigma^{\prime} \frac{\partial C}{\partial S}\right] d S
$$

Since $(1-\sigma)=\sigma^{\prime}$ and $\beta=-\beta_{S}(1-S)$, the absolute value of the first term is greater than the absolute value of the second term. Hence $\partial A / \partial S<0$.

The last ingredient of our analysis is given by the board's optimal choice of $S$. Given $C$, in period $t=1$ non-executives choose $S$ so as to maximise the expected value of the firm. Namely;

$$
\hat{\Pi}=S\{\beta 0+(1-\beta) \pi\}+(1-S)\{(1-\beta) \pi-\beta b[1-A(1-\sigma)]\}-S^{2} / 2
$$

where $\beta$ is given by (3.1) because high earnings are reported by the incumbent. The above expression comes down to

$$
\hat{\Pi}=\pi(1-\beta)-b \beta(1-S)[1-A(1-\sigma)]-S^{2} / 2
$$

The intuition for this equation is the following. With probability $(1-\beta)$, reported high earnings are not falsified and shareholders collect long-term benefits $\pi$. With probability $\beta[S+(1-S) A(1-\sigma)]$, there 
is flawed implementation but the incumbent CEO is replaced owing to successful strategy/operational or accounting/financial oversight by the board. In either case shareholders obtain zero. Finally, with probability $\beta(1-S)[1-A(1-\sigma)]$ shareholders lose $b$ because the manager fabricates earnings and the accounting trick remains undetected (i.e., the audit is ineffective or never takes place). The FOC is thus given by

$$
\hat{S}^{*}=b \beta[1-A(1-\sigma)]
$$

Equation (4.5) confirms that, other things being equal, both surveillance mechanisms are "substitutes": the marginal return to B's strategic involvement decreases with the probability of audit. Hence auditing-led boards may get divorced from strategy, which can be detrimental for the health of the business. Interestingly enough, this occurs even though the two scrutiny devices do not directly compete for board members' time or attention - they are neither complements nor substitutes in the NED's personal cost function. While business-led boards have the capacity to spot flawed strategies more effectively, the extra effort only pays off if the accounting trick doesn't pop up during the audit of the accounts. Consequently, heightened auditing pressure and tighter formal control systems may ultimately discourage NEDs' strategic thinking.

The first-order conditions $(4.2)-(4.5)$ imply that: ${ }^{17}$

$$
\begin{aligned}
\hat{A}^{*} & =\frac{b \beta(1-\sigma)(1-b \beta)}{1-[b \beta(1-\sigma)]^{2}} \\
\hat{C}^{*} & =\beta\left\{\frac{b(1-\sigma)(1-b \beta)}{1-[b \beta(1-\sigma)]^{2}}\right\}^{2}=\left(\hat{A}^{*}\right)^{2} / \beta \\
\hat{S}^{*} & =\frac{b \beta\left[1-b \beta(1-\sigma)^{2}\right]}{1-[b \beta(1-\sigma)]^{2}}
\end{aligned}
$$

Some basic features of the above equilibrium configuration are worth pointing out. First, we have that $\hat{A}^{*}<\hat{S}^{*}$. Underlying this result is the supposition that board's strategic engagement is a relatively more effective surveillance device because it does not attract managerial influence activity. The flip side, of course, is that the board's expert knowledge is much more difficult to verify and eventually enforce in court. Had we assumed a conflict of interest between non-executives and shareholders (e.g., moral hazard), the latter could have found it convenient to put more weight on a verifiable probability of audit in order to promote management accountability. In this way, the extent of monitoring performed by board members can be better enforced. The fact that $\hat{A}^{*}$ is bounded away from zero is also interesting. The absence of a corner solution is obviously an artifact of our assumption concerning cost functions. What seems more important though is the idea that both scrutiny mechanisms entail costs and companies might not find it optimal to completely avoid the one that gives rise to influence activities. Even though non-executives may suspect that senior executives are distorting the financial information they produce, wiping out M's book-cooking

\footnotetext{
${ }^{17}$ Notice that second-order conditions automatically hold.
} 
influence activity can be prohibitively costly for firms (as much as completely eradicating tax fraud or crime can in fact be detrimental for society as a whole).

Equations (4.6) - (4.8) characterise interior solutions when non-executives face no constraint whatsoever in their optimal choice of endogenous variables. In the next section, however, we turn to policy implications of our analysis. Particularly, we interpret the probability of audit $A$ as a variable influenced by a regulatory agency concerned with the extent of misrepresentation and responsible for enforcing financial disclosure rules (e.g., the FSA, LSE or SEC). Alternatively, this compliance obligation could stem from reporting requirements imposed by formalised codes of best practice (e.g., the UK Combined Code or the US SarbanesOxley Act). In any case, what really matters is that the prevailing corporate governance climate in the firm's environment imposes a mandatory level of auditing intensity NEDs must comply with.

\subsection{The effect of tighter compliance mandates}

Consider a situation in which $A \geq \bar{A}$ owing to a shift in the institutional environment for corporate governance that sets an enforceable minimum level of audit intensity. Particularly, let us focus on the case where $\hat{A}^{*}<\bar{A}$ - the regulatory constraint is binding in equilibrium. In this context, it seems natural to think of $\bar{A}$ as stringent governance mandates the Audit Committee of the board of directors must comply with. Then, as in the simpler construct of Section 3, equation (4.3) implies that the level of book-cooking effort spent by the firm's senior management rises. This is because the marginal return to the CEO influence activity goes up. Yet, an additional effect arises which is that board members also alter their level of engagement in the strategic direction of the company. This is evident from (4.5). Less clear is the exact direction of the change in NEDs' strategic involvement, though, because while the probability of an audit increases, its actual "effectiveness" $A(1-\sigma)$ need not do so.

In that connection, the next comparative-static result formally records the equilibrium responses of B's involvement in strategy and M's book-cooking activity to an exogenous regulatory reform that sets a (binding) lower bound on $A$.

Proposition 4 When non-executive directors must comply with the requirement $A \geq \bar{A}>\hat{A}^{*}$, we have that:

1. Non-executives' strategic engagement plummets, i.e. $\bar{S}^{*}<\hat{S}^{*}$.

2. Senior management's book-cooking influence activity goes up, i.e. $\bar{C}^{*}>\hat{C}^{*}$.

Proof. Compute the total differential of $(4.3)-(4.5)$ to obtain:

$$
\left[\begin{array}{cc}
1 & -b \beta A \sigma^{\prime} \\
b A \sigma^{\prime} & 1-b(1-S) A \sigma^{\prime \prime}
\end{array}\right]\left[\begin{array}{l}
d S \\
d C
\end{array}\right]=\left[\begin{array}{c}
-b \beta(1-\sigma) d A \\
b(1-S) \sigma^{\prime} d A
\end{array}\right]
$$


Let $\Delta>0$ be the determinant of the first matrix on the l.h.s. of this expression. Then, straightforward applications of Cramer's rule and the Implicit Function Theorem imply that

$$
\begin{aligned}
& \frac{\partial S}{\partial A}=\frac{-b \beta(1-\sigma)-b^{2} \beta(1-S) A(1-\sigma)^{2}+b^{2} \beta(1-S) A(1-\sigma)^{2}}{\Delta}=\frac{-b \beta(1-\sigma)}{\Delta}<0 . \\
& \frac{\partial C}{\partial A}=\frac{b(1-S) \sigma^{\prime}+b^{2} \beta A(1-\sigma)^{2}}{\Delta}>0 .
\end{aligned}
$$

The result for $\partial S / \partial A$ used the fact that $\sigma^{\prime \prime}(1-\sigma)=-(1-\sigma)^{2}$ (see Assumption 1).

As NEDs devote more time and attention to comply with financial reporting and auditing obligations, the incentive to focus on strategy plunges even though the two activities do not directly compete for board members' attention. In consequence, an escalation of financial reporting requirements intended to prevent corporate fraud may, paradoxically, end up boosting management's attempt to influence the firm's formal control systems. ${ }^{18}$ The reason for this is that compliance intensity and strategic focus are substitutes at the margin: the benefit from an extra unit of strategic engagement decreases with the probability of audit. Thus compliance-led boards get divorced from strategy, which may disturb the necessary balance between management accountability and business health.

To see this, consider the relation between net equity value and B's focus on accounting and auditing matters. Taking the derivative of (4.4) w.r.t. $A$ yields

$$
\frac{\partial \hat{\Pi}}{\partial A}=\{b \beta[1-A(1-\sigma)]-S\} \frac{\partial S}{\partial A}-b \beta(1-S) A \sigma^{\prime} \frac{\partial C}{\partial A}+b \beta(1-S)(1-\sigma)
$$

This shows that compliance has costs and benefits in terms of firm's long-term performance. For one thing, the first two terms in the above equation are negative because $\partial S / \partial A<0$ and $\partial C / \partial A>0$. As the auditing intensity increases, NEDs' understanding of the business falters and boards face a higher business risk of endorsing flawed strategies. This diversion effect is detrimental because NEDs concentrate resources on the relatively less efficient surveillance mechanism. Also, stricter compliance fuels managerial cook-booking activity which in turn diminishes the effectiveness of the auditing procedure. Stricter nominal accountability may weaken effective accountability. For another thing, the last term is positive and reflects the fact that balance sheet reviews do increase the accountability of non-performing managers. The net long-term value of the company is non-monotonic in the probability of audit and it optimal value is characterised by (4.2).

Thus, an upward shift in $A$ owing to corporate governance laws renders the substitute surveillance technology less attractive and NED's strategic focus suffers. Since the manager is in turn more likely to be judged by short-term financial figures, she devotes more attention to (socially wasteful) book-cooking activities. So

\footnotetext{
${ }^{18}$ Goldman and Slezak (2005) also find that certain regulatory changes intended to hamper the fraudulent manipulation of accounting figures can actually fuel misrepresentation. The mechanism at work in their model is completely distinct, though, because it revolves around managerial incentives to manipulate earnings as a result of more intense performance-based pay.
} 
long as there exist states in which non-executives lack sufficient knowledge to evaluate management's longterm business plan, an exogenous increase in the probability of audit actually "fuels" misreporting activities. The reason being that performance metrics based on short-term earnings are more likely to influence B's evaluation of the manager's long-term fit to the company.

Our model gives rise to the following testable predictions.

Proposition 5 When the constraint $A \geq \bar{A}$ is binding in equilibrium, we have the following comparative statics:

1. Expected book-cooking, $\alpha C$, goes up;

2. The probability that a report will be audited, $[p+(1-p) \alpha]$ A, goes up;

3. CEO turnover, $\alpha(1-p)[S+(1-S) A(1-\sigma)]$, could go either up or down.

When board members must comply with a binding probability of audit, the comparative statics of our model are rather different from the ones identified in the previous section. Formally;

Proposition 6 Suppose the constraint $A \geq \bar{A}$ is binding before and after changes in the exogenous variables. Then, we have that:

1. $\partial S / \partial \alpha>0$ and $\partial C / \partial \alpha<0$;

2. $\partial S / \partial p<0$ and $\partial C / \partial p>0$;

3. $\partial S / \partial b>0$ and $\partial C / \partial b \gtrless 0$.

Proof. See Appendix.

When owing to corporate governance reforms the board audits with higher probability than it would otherwise like, non-executives only alter $S$ as a response to changes in the exogenous variables. This in turn impinges on the optimal level of book-cooking effort exerted by management. For example, an increase in the proportion of strategic managers induces more strategic involvement by board members which ultimately discourages management's influence activity. Notice that this conclusion stands in stark contrast to the result obtained in our simple model of Section 3, where more ethical management was always valuable. Likewise, an increase in the likelihood of successful implementation renders executive evaluation less attractive as a surveillance device. As a result, the amount of influence activity goes up. Finally, an upward shift in $b$ induces more strategic engagement by the board whereas the impact on $C$ is generally ambiguous. In effect when $S$ is relatively high an increase in $b$ discourages management's influence activity while the opposite happens when $S$ is relatively small. 


\section{Concluding remarks}

The above results follow from on a number of simplifying modelling assumptions. As always, some are more critical than others. Of particular importance is the absence of credible penalties for managerial misreporting. While somehow restrictive, we do not think this assumption is totally unrealistic. For the major insights of this paper would still obtain had we assumed a positive but finite penalty for false reporting. Further, business cases indicate that often it is difficult and costly to prove top executives' involvement in accounting

fraud in a court due to lax span of accountability along reporting lines. Lower-level managers, who more often than not need to give their consent and carry out the actual alteration of accounting entries, are held responsible for financial fraud but are not necessarily the ones who promote and mainly benefit from the accounting ruse.

Managerial "productive" effort could also be taken on board without necessarily affecting any of our central predictions. In fact, if $\mathrm{M}$ could also take productive actions that increase the probability of sound implementation (i.e., actions that promote shareholders' value), the unrecognised costs of compulsory code compliance might become larger than the ones identified in this paper. The logic is that more audit intensity induces diversion of managerial resources from productive to influence activities, which may be detrimental for both shareholders and society as a whole.

The assumption that NEDs' strategic involvement does not in itself create a corresponding influence activity or efficiency cost for the firm is also debatable. Suffice to say, though, that this need not change our message that stricter financial disclosure obligations fuel managerial book-cooking activities. The main point of departure from the above analysis would be the additional trade-offs taking place, because in the case under consideration the board will not necessarily rely so heavily on its strategic engagement to assess senior management.

In our model managerial book-cooking effort is socially costly insofar as it entails a utility cost for senior management. In reality, these activities could also carry explicit opportunity costs for the firm such as the diversion of valuable physical resources from more productive uses (see, e.g., Goldman and Slezak, 2005). For example, management may be induced to abandon projects that are NPV positive or to cut R\&D spending or expenditures fundamental to running successfully other business lines. To the extent that corporate resources are also diverted from profitable uses in the book-cooking process, the private and social costs of earnings management exceeds the one identified here.

If anything, our model suggests that compliance with enforceable best practice guidelines may be very costly for shareholders. Effectively, stricter financial disclosure requirements may ultimately hamper the performance of the firm. However it is not difficult to ponder plausible scenarios in which increased financial reporting regulation could still bring social gains. For example, an independent and verifiable audit might enable efficient trade with an outsider (a corporate raider) that otherwise would not take place. Alternatively, 
if there is moral hazard at the board level and NEDs' engagement in the business remains unobservable, a verifiable audit might be a feasible way to enforce management accountability. When shareholders suffer from a collective action problem a policy intervention might boost efficiency. 


\section{Appendix}

Proof of Proposition 2. Compute the total differential of (3.2) - (3.3) to obtain:

$$
\left[\begin{array}{cc}
1-b A \sigma^{\prime \prime} & -b \sigma^{\prime} \\
b \beta \sigma^{\prime} & 1
\end{array}\right]\left[\begin{array}{l}
d C \\
d A
\end{array}\right]=\left[\begin{array}{c}
0 \times d \alpha+0 \times d p+A \sigma^{\prime} d b \\
b(1-\sigma) \beta_{\alpha} d \alpha+b(1-\sigma) \beta_{p} d p+\beta(1-\sigma) d b
\end{array}\right]
$$

Let $D>0$ be the determinant of the first matrix on the l.h.s. of this expression. Then, straightforward applications of Cramer's rule and the Implicit Function Theorem imply that

$$
\begin{aligned}
& \frac{\partial C}{\partial \alpha}=\frac{b^{2} \sigma^{\prime}(1-\sigma) \beta_{\alpha}}{D}>0 . \\
& \frac{\partial A}{\partial \alpha}=\frac{\left[1-b A \sigma^{\prime \prime}\right] b(1-\sigma) \beta_{\alpha}}{D}>0 . \\
& \frac{\partial C}{\partial p}=\frac{b^{2} \sigma^{\prime}(1-\sigma) \beta_{p}}{D}<0 . \\
& \frac{\partial A}{\partial p}=\frac{\left[1-b A \sigma^{\prime \prime}\right] b(1-\sigma) \beta_{p}}{D}<0 . \\
& \frac{\partial C}{\partial b}=\frac{A \sigma^{\prime}+b \sigma^{\prime} \beta(1-\sigma)}{D}>0 . \\
& \frac{\partial A}{\partial b}=\frac{\left[1-b A \sigma^{\prime \prime}\right] \beta(1-\sigma)-b A \beta\left(\sigma^{\prime}\right)^{2}}{D}=\frac{\beta(1-\sigma)}{D}>0 .
\end{aligned}
$$

The results for $\partial A / \partial p$ and $\partial A / \partial b$ stem from the fact that $\sigma^{\prime \prime}(1-\sigma)=-\left(\sigma^{\prime}\right)^{2}$ (using Assumption 1).

Proof of Proposition 6. To examine how a change in $\alpha$ affects the equilibrium values of $S$ and $C$, notice that

$$
\left[\begin{array}{cc}
1 & -b \beta A \sigma^{\prime} \\
b A \sigma^{\prime} & 1-b(1-S) A \sigma^{\prime \prime}
\end{array}\right]\left[\begin{array}{l}
d S \\
d C
\end{array}\right]=\left[\begin{array}{c}
b \beta_{\alpha}[1-A(1-\sigma)] d \alpha \\
0
\end{array}\right]
$$

It is readily seen that $\partial S / \partial \alpha>0$ and $\partial C / \partial \alpha<0$. As to a change in $p$, we have that

$$
\left[\begin{array}{cc}
1 & -b \beta A \sigma^{\prime} \\
b A \sigma^{\prime} & 1-b(1-S) A \sigma^{\prime \prime}
\end{array}\right]\left[\begin{array}{l}
d S \\
d C
\end{array}\right]=\left[\begin{array}{c}
b \beta_{p}[1-A(1-\sigma)] d p \\
0
\end{array}\right]
$$

Hence $\partial S / \partial p<0$ and $\partial C / \partial p>0$. Finally, observe that

$$
\left[\begin{array}{cc}
1 & -b \beta A \sigma^{\prime} \\
b A \sigma^{\prime} & 1-b(1-S) A \sigma^{\prime \prime}
\end{array}\right]\left[\begin{array}{l}
d S \\
d C
\end{array}\right]=\left[\begin{array}{c}
\beta[1-A(1-\sigma)] d b \\
(1-S) A \sigma^{\prime} d b
\end{array}\right]
$$

This expression implies that $\partial S / \partial b>0$ and $\partial C / \partial b=A \sigma^{\prime}(1-2 S) \gtrless 0$. 


\section{References}

[1] Bergstresser, D. and Philippon, T. (2006): "CEO Incentives and Earnings Management", Journal of Financial Economics, Forthcoming.

[2] Burkart, M., Gromb, D. and Panunzi, F. (1997): "Large Shareholders, Monitoring, And The Value of The Firm", Quarterly Journal of Economics, Vol. 112 (3), pp. 693-728.

[3] Goldman, E. and Slezak, S. (2005): "An equilibrium model of incentive contracts in the presence of information manipulation", mimeo, University of North Carolina, Chapel Hill.

[4] Graetz, M., Reinganum, J. and Wilde, L. (1986): "The Tax Compliance Game: Toward an Interactive Theory of Law Enforcement", Journal of Law, Economics, \& Organization, Vol. 2 (1), pp. 1-32.

[5] Holmstrom, B. and Milgrom, P. (1991): "Multitask Principal-Agent Analyses: Incentive Contracts, Asset Ownership, and Job Design", Journal of Law, Economics $\mathcal{E}$ Organization, Vol. 7 (Special Issue), pp. 24-52.

[6] Keasey, K., Short, H. and Wright, M. (2005): "The Development of Corporate Governance in the UK", in Corporate Governance (edited by K. Keasey, S. Thompson and M. Wright), Chapter 2, John Wiley $\&$ Sons, England.

[7] Khalil, F. (1997): "Auditing without Commitment", RAND Journal of Economics, Vol. 28 (4), pp. 629-640.

[8] Melumad, N. and Mookherjee, D. (1989): "Delegation as Commitment: The Case of Income Tax Audits", RAND Journal of Economics, Vol. 20 (2), pp. 139-163.

[9] Milgrom, P. and Roberts, J. (1988): "An Economic Approach to Influence Activities in Organizations", American Journal of Sociology, Vol. 94, pp. S154-S179.

[10] Mookherjee, D. and Png, I. (1989): "Optimal Auditing, Insurance, and Redistribution", Quarterly Journal of Economics, Vol. 104 (2), pp. 399-415.

[11] Newman, P., Rhoades, S. and Smith, R. (1996): "Allocating Audit Resources to Detect Fraud", Review of Accounting Studies, Vol. 1, pp. 161-182.

[12] Newman, P., Patterson, E. and Smith, R. (2005): "The Role of Auditing in Investor Protection", The Accounting Review, Vol. 80 (1), pp. 289-313.

[13] Rotemberg, J. and Saloner, G. (2000): "Visionaries, Managers and Strategic Direction", RAND Journal of Economics, Vol. 31 (4), pp. 693-716. 